\section{Research Article}

(C) 2020 Soubhi et.al.. This is an open access article licensed under the Creative Commons Attribution-NonCommercial 4.o International License (https://creativecommons.org/licenses/by-nc/4.o/)

\title{
Substance Use in College Students: A Comparative Study on French and Moroccan Students
}

\author{
Fatima Zahra Soubhi \\ University Hassan II of Casablanca, Morocco \\ Moulay El Mustapha El Berjaoui \\ University Hassan I, Morocco \\ Bouzekri Touri \\ LAPSTICE Laboratory, University Hassan II of Casablanca, Morocco \\ Laurent Lima \\ University Pierre Mandes, France \\ Mohamed Talbi \\ University Hassan II of Casablanca, Morocco
}

Doi: 10.36941/jesr-2020-0oo5

\section{Abstract}

This paper is a comparative study related to the project Volubilis "Moroccan and French students: comparative approach". Volubilis survey is a part of an integrated project between the University of Grenoble Alpes and Hassan II University of Casablanca. This research project aims at collecting data related to students consumption of addictive substances, who enroll in faculty of humanities, economy and sciences of the Universities of the Rhône Alpes region (Lyon and Grenoble) and Hassan II University of Casablanca (e.g. tobacco, alcohol, cannabis...). In order to conduct a comparative study and to come out with effective results. Our sample is made up of 350 students from Hassan II University in Casablanca and 1464 students from Rhône-Alpes universities their average age is 22 years old for both.

Keywords: Quality of Life, Student, addiction, alcohol, tobacco, illegal drugs, comparative.

\section{Introduction and Problem}

In Morocco, the project Volubilis "Moroccan and European students: comparative approach", aims at identifying the difficulties and expectations of Moroccan students. The project Volubilis provides data on the choice of students in third academic year in terms of training, and expectations in relation to studies, training paths, learning strategies, and professional projects. This research aims at enriching the research literature and make it available to educational policy developers, by producing and disseminating more knowledge about students. Data from the EU has been taken into account in order to carry out this study. The Volubilis project focused on student's health, particularly, on 
addictive behavior in both countries; France and Morocco.

In recent years, we have seen an alarming increase in the use of illicit drugs and cannabis among youth in France and Morocco. This phenomenon affects college-level students, who consume addictive substances. Consequently, this has shown its negative effects on their university path resulting in dropping out of school and failure in study.

According to Liddle Et Al. (2008), teenagers face some problems like emotional problems, emotional distancing, isolation, depression, tiredness, irritability, change in level of cooperation, changing in mood, eating, sleeping patterns and memory disorders after taking the drugs.

Cepulkauskaite, (1998) wondered what are the combination of several factors, including society, family and peers. They may turn to drugs to escape stress, loneliness or to overcome shyness in social situations. They may want to be grown up or they may be curious. A young person with low selfesteem may feel they are not smart, attractive, talented or popular at their peers.

Without forgetting that the consumption of alcohol and tobacco cause harmful effects that are related to the degree of consumption by individuals.

The abuse of addictive products affects personal, family, social and professional environment of students who are suffering affective and emotional disorders.

A related survey revealed in the thesis of F.Z Soubhi in 2016, investigated addiction within students of Biology of Hassan II University, faculty of sciences, Ben M'sik, Casablanca, Morocco, and engineering school "ENSAM Casablanca" shows that students of Biology department of Ben M'sik faculty consume drugs more than students of ENSAM.

\section{Method}

Our sample is on addiction in the educational systems of two Universities, 350 students in Morocco and 1,464 in France with an average age of 22 years old.

\subsection{Participants}

\subsubsection{France}

In this study, $1,464,3^{\text {rd }}$ year postgraduates, responded to our survey, $27 \%$ were men and $73 \%$ were women; additionally; they are from different departments and different universities.

The survey was conducted in 2009 on the basis of a paper questionnaire sent by mail to all 3rd year postgraduates ( $\mathrm{L}_{3}$ or 1st year of engineering school) for the universities in Lyon and Grenoble as well as two major schools in the Rhône-Alpes Region.

Table 1: Distribution by gender

\begin{tabular}{|c|c|c|c|c|c|c|c|c|c|c|c|c|}
\hline Gender & $\begin{array}{l}\text { University } \\
\text { Grenoble } 1 \\
\end{array}$ & $\begin{array}{c}\text { University } \\
\text { Grenoble } 2 \\
\end{array}$ & $\begin{array}{c}\text { University } \\
\text { Grenoble } 3 \\
\end{array}$ & Engineering & $\begin{array}{c}\text { University } \\
\text { Lyonı }\end{array}$ & $\begin{array}{c}\text { University } \\
\text { Lyon2 }\end{array}$ & $\begin{array}{c}\text { University } \\
\text { Lyon } 3\end{array}$ & ENS & INSA & Others & $\begin{array}{c}\text { Not } \\
\text { Indicated } \\
\end{array}$ & $\mathrm{To}$ \\
\hline Women & $\begin{array}{c}126 \\
11.93 \%\end{array}$ & $\begin{array}{c}174 \\
16.47 \%\end{array}$ & $\begin{array}{c}96 \\
9.09 \%\end{array}$ & $\begin{array}{c}3 \\
0.28 \%\end{array}$ & $\begin{array}{c}149 \\
14.10 \%\end{array}$ & $\begin{array}{c}364 \\
34.46 \%\end{array}$ & $\begin{array}{c}67 \\
6.34 \%\end{array}$ & $\begin{array}{c}14 \\
1.32 \%\end{array}$ & $\begin{array}{c}24 \\
2.27 \%\end{array}$ & 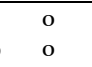 & $\begin{array}{c}39 \\
3.69 \%\end{array}$ & \\
\hline Mer & $\begin{array}{c}76 \\
19.48 \%\end{array}$ & $\begin{array}{c}37 \\
9.48 \%\end{array}$ & $\begin{array}{c}10 \\
2.56 \%\end{array}$ & $\begin{array}{c}1 \\
0.25 \%\end{array}$ & $\begin{array}{c}85 \\
21.79 \%\end{array}$ & $\begin{array}{c}79 \\
20.25 \%\end{array}$ & $\begin{array}{c}34 \\
8.71 \%\end{array}$ & $\begin{array}{c}14 \\
3.58 \%\end{array}$ & $\begin{array}{c}43 \\
11.02 \%\end{array}$ & $\begin{array}{c}1 \\
0.25 \%\end{array}$ & $\begin{array}{c}10 \\
2.56 \%\end{array}$ & $\begin{array}{c}390 \\
100 \%\end{array}$ \\
\hline Total & $\begin{array}{c}202 \\
13.96 \% \\
\end{array}$ & $\begin{array}{c}211 \\
14.59 \% \\
\end{array}$ & $\begin{array}{c}106 \\
7 \cdot 33 \% \\
\end{array}$ & $\begin{array}{c}4 \\
\text { o.27\% } \\
\end{array}$ & $\begin{array}{c}234 \\
16.18 \% \\
\end{array}$ & $\begin{array}{c}443 \\
30.63 \% \\
\end{array}$ & $\begin{array}{c}101 \\
6.98 \% \\
\end{array}$ & $\begin{array}{c}28 \\
1.93 \% \\
\end{array}$ & $\begin{array}{c}67 \\
4.63 \% \\
\end{array}$ & $\begin{array}{c}1 \\
0.06 \%\end{array}$ & $\begin{array}{c}49 \\
3.38 \% \\
\end{array}$ & $\begin{array}{r}1446 \\
100 \% \\
\end{array}$ \\
\hline
\end{tabular}

\subsubsection{Morocco}

Surveys have been developed within the Moroccan university and the engineering school in order to get a wide spread knowledge about this phenomenon among Moroccan university students. The population targeted by the pilot survey composed of students in the third year of the first cycle LMD, 
who major in the following disciplines: Linguistics and Literature, Economics and Experimental Sciences. The questionnaires were handed out to 256 students who answered the survey. The respondents were $31 \%$ of men and $69 \%$ of women with an average age of 22 years old.

The survey was conducted in November 2011. The researcher made sure that the questionnaires were distributed in the different sectors by respecting the students timetable. After the students consent was granted, the purpose of the research was presented to them and the questions were explained. After answering the questions, the researchers retrieved the questionnaires from the first slice of the samples in March and then in December 2012.

The duration of 3 years that separated the first and second investigation was due to the adaptation of the questionnaires to the Moroccan context, the availability of students and translation of questionnaires.

Table 2: Distribution by gender

\begin{tabular}{lc}
\hline Gender & University Hassan II of Casablanca \\
\hline Women & 169 \\
& $65 \%$ \\
Men & 88 \\
& $34.24 \%$ \\
Total & 257 \\
& $100 \%$ \\
\hline
\end{tabular}

\subsection{Material}

\subsubsection{France}

The questionnaire includes 425 levels of items divided into 73 questions and organized according to 14 themes (1 Specialty and access to tertiary institutions, 2 Choice of training and expectations for studies, 3 Education and teaching; Learning and work behaviours 5 Examinations and time spent at work 6 Questions about student life 7 Contacts and communication 8 Experiences and problems in studies 9 Development and improvement of higher education; 10 Choice of profession and representations of the future profession, 11 values and judgments, 12 Housing, 13 Health, 14 Personal data). The vast majority of the questions are closed the questions proposing a scale (agreement, importance, utility, interest, frequency) at 7 levels (rated from o to 6). The questionnaire also includes some open numerical questions (marks obtained, time spent on academic activities, age, etc.).

\subsubsection{Morocco}

The Moroccan team conducted the national research using the same instruments applied by the French part, namely the questionnaire mentioned earlier. The group of Moroccan researchers realized the translation of the questionnaire and its adaptation to the linguistic and cultural of Moroccan context.

The Volubilis questionnaire is grouped into 15 themes, including health, which has a section on addictive behaviours.

\section{Analyse}

After collecting the data, we used SPSS to analyze the data. 


\section{Results}

\subsection{General \\ 4.1.1 Tobacco}

The results of the questionnaire related to the two universities according to the disciplines of letter and humanities, economy and science showed that tobacco consumption among Moroccan students are higher than the French students (37.40\%) against (20.20\%).
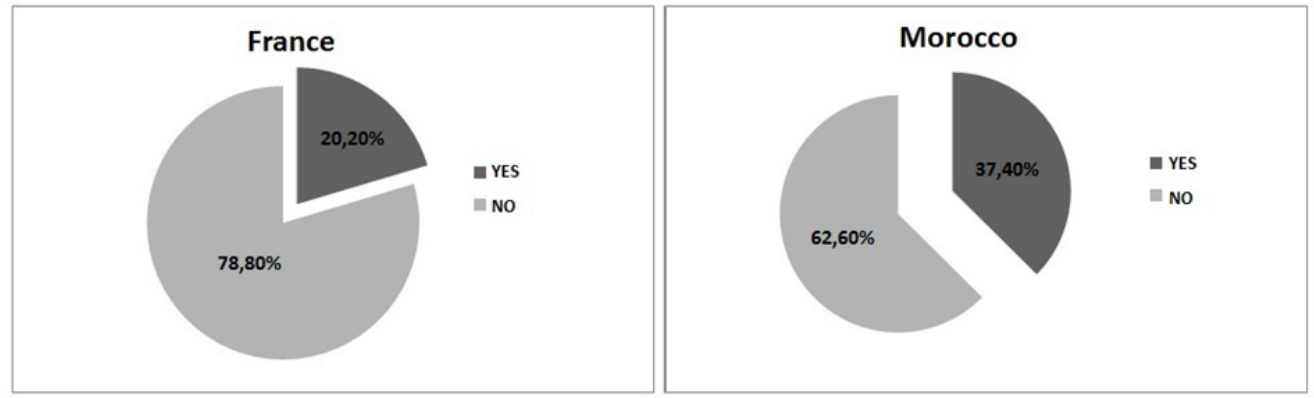

Graph 1 : Consumption of Tobacco in France and Morocco.

\subsubsection{Alcohol}

The results on tobacco revealed a high consumption by Moroccan students (37.40\%), whereas that of alcohol remains at $(35.20 \%)$ for student consumers.

In contrast to tobacco use, this remained fairly low among French people with only (20.20\%) that of alcohol which was significantly higher with $(55.80 \%)$ of student consumers.

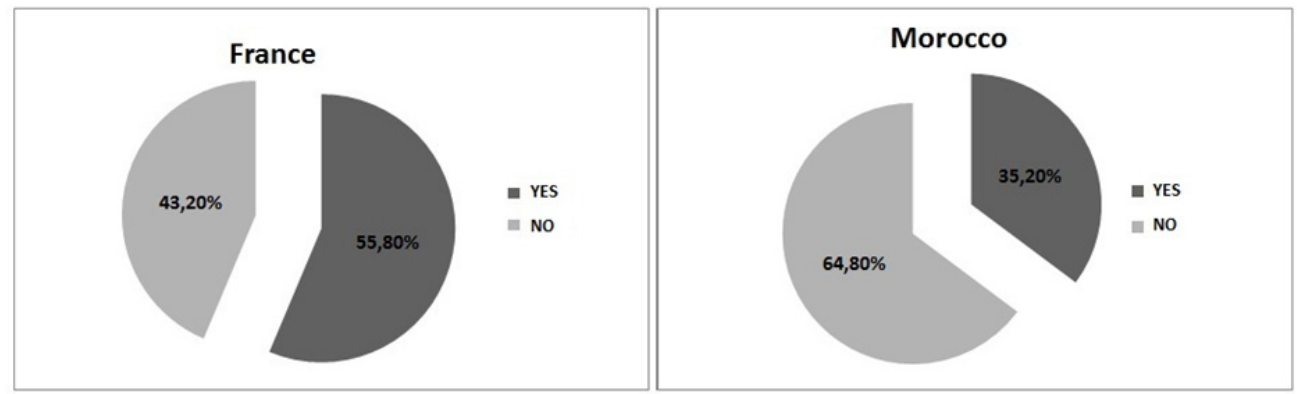

Graph 2: Consumption of Alcohols in France and Morocco

\subsubsection{Tranquilizers, anti-depressants}

The survey showed a high consumption of tranquilizers or anti-depressants among Moroccan students with $(40.70 \%)$ having consumed them, compared to only $(7.30 \%)$ in France. 

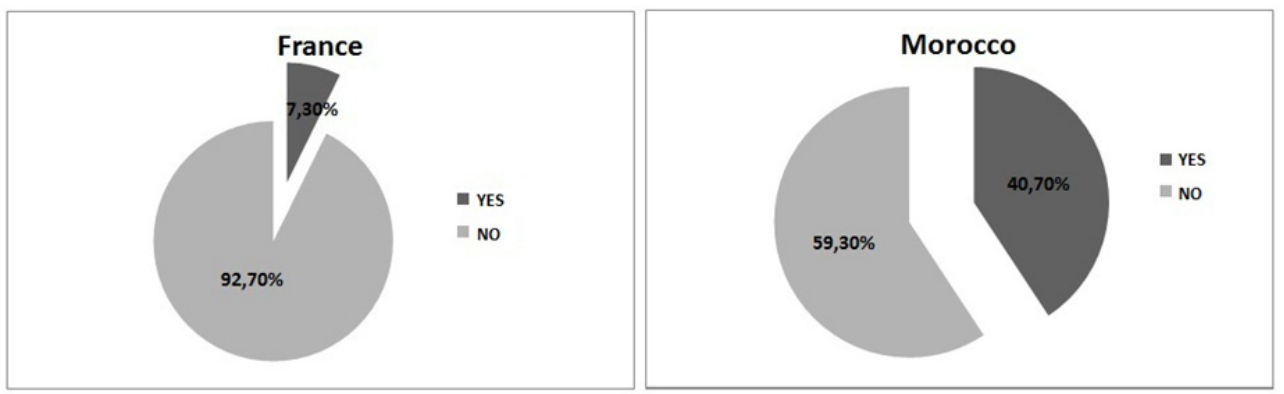

Graph 3 : Consumption tranquilizers, antidepressants in France and Morocco

\subsubsection{Cannabis}

The consumption of Cannabis is the same rate that of tobacco and alcohol with (37.90\%) consumed by Moroccan students, compared to only $(8.20 \%)$ consumed by French students.

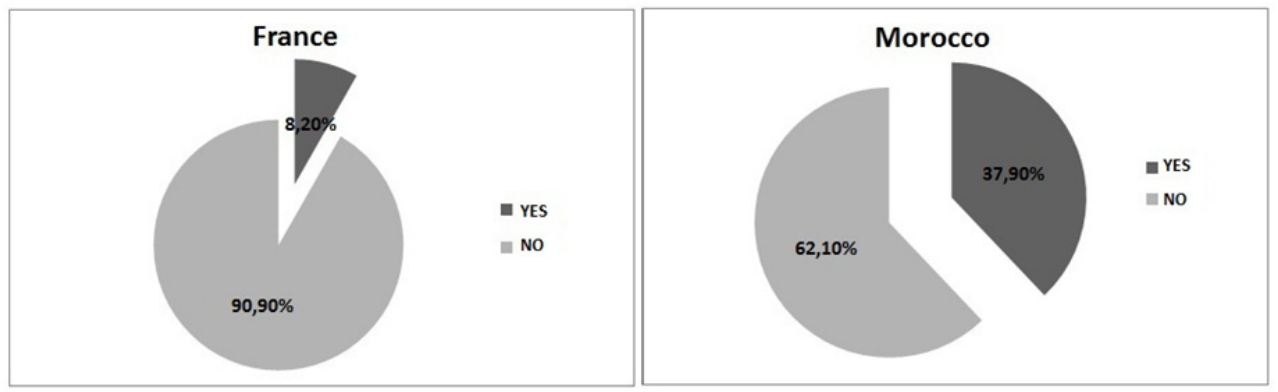

Graph 4: consumption of cannabis in France and Morocco

\subsubsection{Other drug}

Regarding other illicit drugs $(37.90 \%)$ of Moroccan students surveyed said they consumed a substance, compared to only (1.40\%) of students in France.

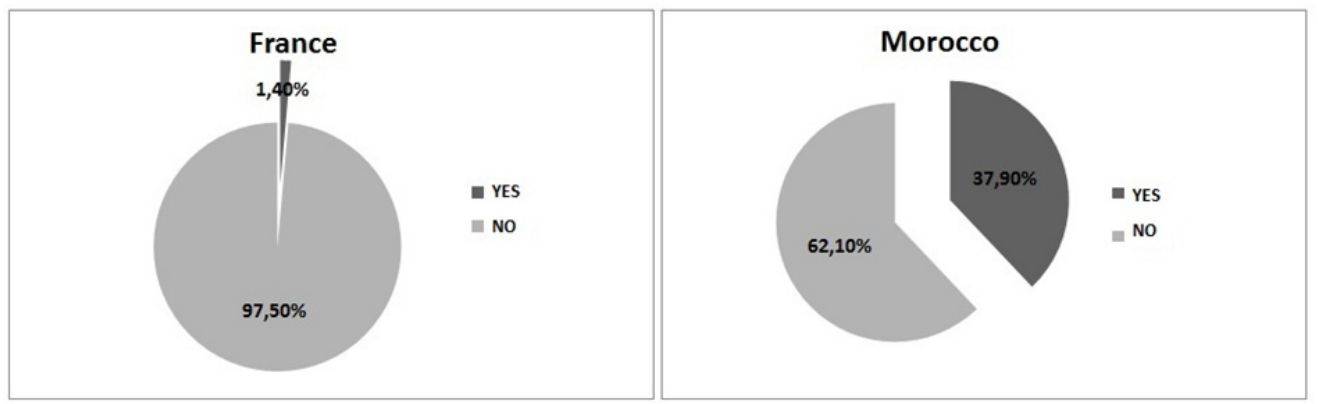

Graph 5 : Consumption of other drugs in France and Morocco 


\subsection{Discipline}

The comparison concerns students belonging to the disciplines of languages, arts, economics and mathematics, i.e., 256 Moroccan students and 627 Rhônalpins.

It seemed that membership in the Faculty of Arts or Economics in Morocco has a significant impact on tobacco consumption. We noted that tobacco consumption concerned ( $70 \%$ ) of economics students and $(48.2 \%)$ of students of letters compared to the low tobacco consumption among scientists (12.4\%).

In France, although tobacco consumption is lower than in Morocco, there was still a higher consumption of tobacco among students belonging to the faculties of Letters (18.7\%) and Science $(17 \%)$ compared to economics $(13.8 \%)$.

Table 3: Consumption of Tobacco in France and Morocco according to discipline

\begin{tabular}{lcccccc}
\hline & \multicolumn{2}{c}{ Letter } & \multicolumn{3}{c}{ Tobacco } & \multicolumn{2}{c}{ Economy } \\
& Yes & No & Yes & No & Yes & No \\
France & $18.7 \%$ & $81.3 \%$ & $17 \%$ & $83 \%$ & $13.8 \%$ & $86.2 \%$ \\
Morocco & $48.2 \%$ & $51.8 \%$ & $12.4 \%$ & $87.6 \%$ & $70 \%$ & $30 \%$ \\
\hline
\end{tabular}

It seemed that belonging to one or another university discipline in Morocco had a significant impact on alcohol consumption by nearly $(76.8 \%)$ of economics students reporting drinking alcohol. This consumption was lower for students of Letters (36.4\%) and even lower of science students (11.5\%).

More than half of the students belonging to the faculties of science, literature and economics in France claimed to have consumed alcohol.

Table4: Consumption of Alcohol in France and Morocco according to discipline

\begin{tabular}{lcccccc}
\hline & \multicolumn{2}{c}{ Letter } & \multicolumn{2}{c}{ Alcohol } & \multicolumn{2}{c}{ Economy } \\
& Yes & No & Yes & No & Yes & No \\
France & $52.3 \%$ & $47.7 \%$ & $57.7 \%$ & $42.3 \%$ & $52.2 \%$ & $47.5 \%$ \\
Morocco & $36.4 \%$ & $63.6 \%$ & $11.5 \%$ & $88.5 \%$ & $76.8 \%$ & $\mathbf{2 3 . 2} \%$ \\
\hline
\end{tabular}

There was a high consumption of tranquilizers without a medical prescription among students of economics in Morocco (86\%), which might be due to the high failure rate in this discipline. This consumption was lower among letter-language students (44.4\%). \%), and even lower among science students (13.5\%).

It appeared that faculty members in France had a low impact on tranquilizer and antidepressant use, which varies between (7.2\%) of students involved in Letters and (2.5\%) in Economics $3.2 \%$ in sciences). This indicated an overall lower consumption levels across all faculty members.

Table 5: Consumption of Tranquilizers, antidepressants in France and Morocco according to discipline

\begin{tabular}{lcccccc}
\hline & \multicolumn{3}{c}{ Tranquilizers, anti-depressants } & \multicolumn{2}{c}{ Economy } \\
& Yetter & No & Yes & No & Yes & No \\
France & $7.2 \%$ & $92.8 \%$ & $3.2 \%$ & $96.8 \%$ & $\mathbf{2 . 5} \%$ & $97.5 \%$ \\
Morocco & $44.4 \%$ & $55.6 \%$ & $13.5 \%$ & $86.5 \%$ & $86 \%$ & $14 \%$ \\
\hline
\end{tabular}

There was high cannabis use among Moroccan students in the Faculty of Economics (86.7\%) with 
a lower level in Letters (36.5\%), and an even lower for Science students (8.9\%). In France, cannabis use did not exceed (6\%) for all disciplines.

Table 6: Consumption of Cannabis in France and Morocco according to discipline

\begin{tabular}{lcccccc}
\hline & \multicolumn{2}{c}{ Letter } & \multicolumn{2}{c}{ Cannabis } & \multicolumn{2}{c}{ Economy } \\
& Yes & No & Yes & No & Yes & No \\
France & $6 \%$ & $94 \%$ & $5.8 \%$ & $94.2 \%$ & $6.2 \%$ & $93.8 \%$ \\
Morocco & $36.5 \%$ & $63.5 \%$ & $8.9 \%$ & $91.1 \%$ & $86.7 \%$ & $13.3 \%$ \\
\hline
\end{tabular}

There was high drug consumption among Moroccan students belonging to the Faculty of Economics (83.1\%). Even though this may be considered high, it is significantly lower in Letters (41.2\%) with an even lower level for science students (9.7\%). In France, the consumption of drugs did not exceed (2\%) for all disciplines.

Table 7: Consumption of other drug in France and Morocco according to discipline

\begin{tabular}{lcccccc}
\hline & \multicolumn{2}{c}{ Letter } & \multicolumn{3}{c}{ Other drugs } & \multicolumn{2}{c}{ Economy } \\
& Yes & No & Yes & No & Yes & No \\
France & $0.9 \%$ & $99.1 \%$ & $1.9 \%$ & $98.1 \%$ & $1.2 \%$ & $98.8 \%$ \\
Morocco & $41.2 \%$ & $58.8 \%$ & $9.7 \%$ & $90.3 \%$ & $83.1 \%$ & $16.9 \%$ \\
\hline
\end{tabular}

\subsection{Gender}

The consumption of tobacco was more common among women in Morocco ( $38.6 \%$ compared to $34.7 \%$ among men). In contrast, in France, smoking was more common among men (23.4\%) than among women (19.4\%).

Table 8: Consumption of Tobacco in France and Morocco according to gender

\begin{tabular}{lcccc}
\hline & \multicolumn{3}{c}{ Tobacco } & \multicolumn{2}{c}{ Woman } \\
& Yes & No & Yes & No \\
France & $23.4 \%$ & $76.6 \%$ & $19.4 \%$ & $80.6 \%$ \\
Morocco & $34.7 \%$ & $65.3 \%$ & $38.6 \%$ & $61.4 \%$ \\
\hline
\end{tabular}

Alcohol consumption was more common among women in Morocco (36.3\% compared to 31.1\% among men). On the other hand, in France alcohol consumption was more frequent in men (63.5\%) than in women $(54 \cdot 1 \%)$.

Table 9: Consumption of Alcohol in France and Morocco according to gender

\begin{tabular}{lcccc}
\hline & \multicolumn{3}{c}{ Alcohol } & \multicolumn{2}{c}{ Women } \\
& Yes & No & Yes & No \\
France & $63.5 \%$ & $36.5 \%$ & $54.1 \%$ & $45.9 \%$ \\
Morocco & $31.1 \%$ & $68.9 \%$ & $36.3 \%$ & $63.7 \%$ \\
\hline
\end{tabular}

According to the results of this study, In Morocco, tranquillizers and antidepressants were among the benefits women consume ( $44.8 \%$ compared to $29.7 \%$ for men). The same was true in France with 
$7 \cdot 4 \%$ of women consuming a tranquilizer or antidepressant product compared with $3.3 \%$ of men.

Table 10: Consumption of Tranquillizers and anti-depressants in France and Morocco according to gender

\begin{tabular}{lcccc}
\hline \multicolumn{5}{c}{ Tranquillizers and antidepressants } \\
& Mes & No & Yes & Nomen \\
France & $3.3 \%$ & $96.7 \%$ & $7.4 \%$ & $92.6 \%$ \\
Morocco & $29.7 \%$ & $70.3 \%$ & $44.8 \%$ & $55.2 \%$ \\
\hline
\end{tabular}

The consumption of Cannabis in Morocco is more common among women (38.9\% vs. 32.0\% for men). In France, however, cannabis use is higher among men (12.6\% versus $6.7 \%$ for women).

Table 11: Consumption of cannabis in France and Morocco according to gender

\begin{tabular}{lcccc}
\hline & \multicolumn{3}{c}{ Cannabis } & \multicolumn{2}{c}{ Women } \\
& Yes & No & Yes & No \\
France & $12.6 \%$ & $87.4 \%$ & $6.7 \%$ & $93.3 \%$ \\
Morocco & $32 \%$ & $68 \%$ & $38.9 \%$ & $61.1 \%$ \\
\hline
\end{tabular}

We noted higher drug consumption among Moroccan students (39.4\% against 31.1\% of students). On the other hand, in France, consumption was more frequent for (2.4\%) students than for (1.1\%) for female students.

Table 12: Consumption of other drug in France and Morocco according to gender

\begin{tabular}{lcccc}
\hline \multicolumn{3}{c}{ Men } & \multicolumn{2}{c}{ Women } \\
France & Yes & No & Yes & No \\
Morocco & $2.4 \%$ & $97.6 \%$ & $1.1 \%$ & $98.9 \%$ \\
\hline
\end{tabular}

\section{Discussion}

This corpus demonstrated that addiction to alcohol, tobacco, tranquilizers, cannabis and other drugs is a fact for many students. It underlined an overconsumption by Moroccan students compared to French ones mainly of tobacco ( 1.8 times more), antidepressants ( 5.6 times more), cannabis (4.6 times more) and especially other drugs (27 times more). Only alcohol consumption is more common in France than in Morocco (1.6 times more).

These differences in consumption between the two countries regarding tobacco are due to lack of awareness of its danger and allowing its consumption in campus areas. Whereas antidepressants became a way out to stressful and overloaded work studies. Cannabis availability turned its consumption much easier for students and especially for those on their way to dropping out.

Finally, other drugs that are mainly represented by psychotropic drugs are over-consumed due to their cheap prices and their availabilities in the campus areas.

A survey, showing tobacco, alcohol, cannabis and other drugs addictions impacting overall health, had investigated students' health and reported that $9.96 \%$ were suffering bad health (F.Z. Soubhi \& al, 2015). Most of those students in the survey reported presence of addiction and stress.

In another study, only $25 \%$ of students feel comfortable practicing public speaking whereas $75 \%$ feel the opposite (Sabir B, Touri B, Moussetad M, 2016). In an investigation on students suffering 
social withdrawal, the results showed that they have been experiencing addiction (B. Touri \& T. Marquardt, 2009).

It's vivid, nowadays, that a young man without any qualifications, surely, faces difficulties in professional integration. Thus, it's of salience and of highly importance to know deeply what, exactly, causes dropout of school. Scholars of education are concerned with the main factors lead to students' success or failure and they are also interested in what causes some students succeed in their careers while the others not.

Some studies (Barbara Et Al, 1988) provide evidence that consumption of drugs, mentioned above, have an impact on students' academic performance, which leads to academic failure and constraints in professional and social inclusion. Moreover, other studies (Valkov, 2018) provide evidence that drugs use needs to be considered as a main factor that precedes school dropout.

\section{Acknowledgments}

This paper was prepared based on Hubert Curien's research project "Moroccan and European Students: A Comparative Approach" (W 22670ZE).

\section{Reference}

B. Touri \& Thomas Marquardt, 2009, ASHA Convention, Louiziana, USA.

Barbara S. Mensch. Denise B. Kandel. (1988). Sociology of Education .Vol. 61, No. 2, pp. 95-113

Cepulkauskaite I. (1998). Addiction of Teenagers: Myth or Reality? Drug Addiction And Prevention College Essay, 141-160.

F.Z. Soubhi, (2016). "Difficultés et troubles d'apprentissages et de communication: facteurs expansifs affectant les parcours académiques des étudiants scientifiques", Thesis. University Hassan II of Casablanca.

Liddle, H. A., Hogue, A., Dauber, S., Chinchilla, P., Fried, A., Henderson, C., Inclan, J., Reiner, R. H., \& (2008). Assessing fidelity in individual and family therapy for adolescent substance abuse. Journal of Substance Abuse Treatment, 35, 137-147.

Sabir, S. Touri, B. Moussetad, M. (2019). Development of a Minimum Protocol for the Assessment of Communication Disorders within Moroccan Students. The Open Public Health Journal, ISSN: 1874-9445 — Volume 12.

Soubhi, F.Z., Lima, L., Knouzi, N., Talbi, M. (2015). Learning difficulties related of health status of Moroccan students. Procedia - Proceedia Social and Behavioral Sciences, 197, 1507 - 1511 . doi: 10.1016/j.sbspro.2015.07.102.

Valkov, P. (2018). School dropout and substance use: consequence or predictor? . Trakia Journal of Sciences, No 2, pp 95-101. doi:10.15547/tjs.2018.02.004 